\title{
The use of two microbiotests to evaluate the toxicity of sediment from Mpumalanga, South Africa
}

\author{
YC Cloete ${ }^{1 *}$, BF Shaddock ${ }^{1}$ and A Nel ${ }^{2}$ \\ 'Golder Associates Research Laboratory, Midrand, P.O. Box 6001, Halfway House 1685, Midrand, South Africa \\ ${ }^{2}$ Department of Zoology, University of Johannesburg, P.O. Box 524, Johannesburg, South Africa
}

\begin{abstract}
Rapid urbanisation throughout the world has resulted in numerous ecological and environmental problems. The release of contaminants into the aquatic environment and the subsequent accumulation in sediment is a specific area of concern due to the potential re-release of the contaminants into solution. The responses of two microbiotests designed to evaluate sediment toxicity (the Ostracodtoxkit F and Phytotoxkit test) were compared once exposed to three samples collected in the vicinity of a power station in Mpumalanga, South Africa. Sediment characterisation and chemical analyses were conducted in order to determine possible correlations with the expressed results. Where possible, the concentration of chemicals in the sediment was compared to available sediment guidelines. The study showed that whilst the Phytotoxkit test results did not indicate any acute toxicity ( $<50 \%$ inhibition), the Ostracodtoxkit $\mathrm{F}$ test indicated $100 \%$ mortality at the upstream site, with increased growth inhibition at the remaining two sites. The concentration of chrome at all three sites exceeded the interim sediment quality guidelines $(37 \mathrm{mg} / \mathrm{kg})$, with the sample collected at the upstream site exceeding the probable effect level $(90 \mathrm{mg} / \mathrm{kg})$. The findings from this study indicated that the Phytotoxkit and Ostracodtoxkit F test kits are sensitive enough to evaluate sediment toxicity.
\end{abstract}

Keywords: Ostracodtoxkit F, Phytotoxkit, sediment contamination

\section{INTRODUCTION}

Metals (e.g. V, Cd, $\mathrm{Pb}$ and $\mathrm{N}$ ) and nutrients $\left(\mathrm{P}, \mathrm{N}\right.$ and $\mathrm{NH}_{4}^{+}$) can enter the aquatic environment (Dallas and Day, 2004) through naturally occurring events as well as anthropogenic activities. Both pollutants and contaminants can accumulate in the sediment and may be re-released into the overlying water through chemical, physical and biological processes. This release of contaminants back into solution places the health of the aquatic environment at risk (Lin et al., 2003; Gimenez et al., 2013). The mobility of sediment is slow; therefore sitespecific contaminated sediments are less likely to change over a short time period, whereas site water can only give a snapshot indication of the potential effect of contaminants (Jain et al., 2012). Various microbiotests have been developed over the years to assess the toxicity of sediment (CzerniawskaKusza et al., 2006), and the use of microbiotests is becoming an important tool in ecological assessments (Blaise, 1991). According to Blaise (1991), the advantages of microbiotests are that these tests are sensitive, rapid and reproducible, requiring only a small sample volume when compared to other available bioassays. The Ostracodtoxkit $\mathrm{F}$ using the species Heterocypris incongruens has been used previously by Latif and Licek (2004) to assess wastewater and river sediment; Torokne and Toro (2010) to assess river sediment and Kudłak et al. (2011) to evaluate the toxicity of heavy metals. The Phytotoxkit test is conducted using three plant species (Lepidium sativum, Sinapis alba and Sorghum saccharatum). This test kit has been used by Czerniawska-Kusza et al. (2006) to evaluate the toxicity of

\footnotetext{
* To whom all correspondence should be addressed.

+27 11 672-0666; e-mail: ycloete@golder.co.za

Received 28 February 2014; accepted in revised form 26 May 2017
}

canal sediment; Czerniawska-Kusza and Kusza (2011) to test the toxicity of reservoir sediment and Van der Vliet et al. (2012) to evaluate various pollutants. Currently in South Africa there are no standardised methods to evaluate the status of potentially contaminated sediments. This study was conducted as a preliminary assessment of two microbiotests to evaluate their application in sediment toxicity testing by using potentially contaminated sediment collected from sites in Mpumalanga Province, South Africa.

\section{MATERIALS AND METHODS}

The study area is located in the vicinity of a power station in close proximity to coal mining and metal industries in the Mpumalanga Province of South Africa. An open-cast coal mine is situated approximately $8 \mathrm{~km}$ from the 'upstream site'; the difference in elevation between the opencast coal mine and the upstream site is approximately $80 \mathrm{~m}$ with the coal mine being at the higher elevation. A tributary of the main river runs next to the opencast mine. Agricultural activities are present between the opencast mine and the main river. A railway line passes the opencast mine and crosses over the section of river where the upstream site is situated. The effluent release point is situated at the power station. The distance between the upstream site and effluent release point, and from the effluent release point to the downstream site is approximately $12 \mathrm{~km}$ each. Sites were selected in order to evaluate the potential impact of a power station on aquatic sediments (up- and downstream of the power station as well as at the effluent release point (ERP)). Approximately $2.5 \mathrm{~kg}$ of the river sediment was collected from each of the sites and transported to the Golder Associates Research Laboratory (GARL) within $48 \mathrm{~h}$ of collection. Sediment was collected from the top $2 \mathrm{~cm}$ of the river bed with an inert plastic scoop, as most epibenthic organisms and the most recent contaminant 


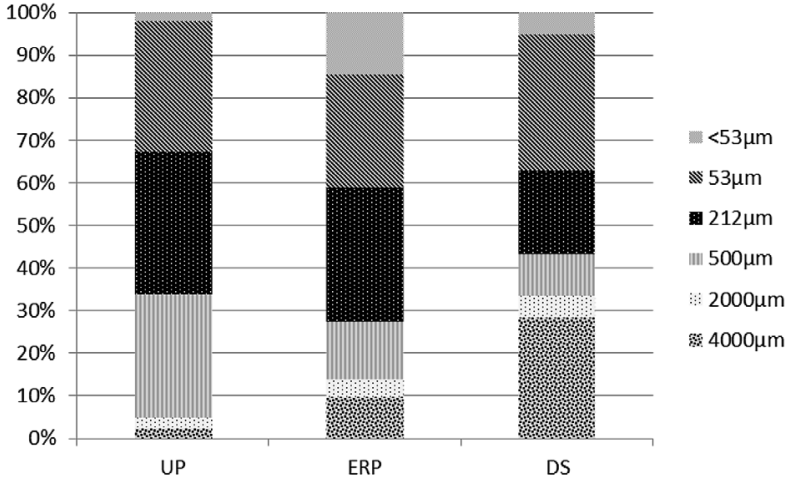

Figure 1

Sediment grain size $(\mu \mathrm{m})$ distribution for the three sites (UP: upstream site; ERP: effluent release point; DS: downstream site)

deposition will be present in this section of the sediment (Simpson et al., 2005). The sediment was dried for 4 days at $35^{\circ} \mathrm{C}$ and homogenised in order to determine the physical characteristics (grain size distribution, total organic content ((TOC) through loss-on-ignition) as well as total metal content (ICP-OES: Aqua Regia). Additional homogenised sediment was prepared according to the standard operating procedures (SOP) for each sediment bioassay. Phytotoxkit test exposures were carried out according to the SOP of the test kit (Phytotoxkit, 2004). Seeds of 2 dicotyledonous species (L. sativum and S. alba) and a monocotyledon species (S. saccharatum) were exposed in triplicate to evaluate the sediment $\left(72 \mathrm{~h}\right.$ in darkness at $25^{\circ} \mathrm{C}$ $\pm 2^{\circ} \mathrm{C}$ ) and control sediment similar in composition to OECD reference sediment (sand, kaolin and peat). Images of exposure plates were captured using a flatbed scanner and root lengths were measured with UTHSCSA ImageTool (Version 3) software. Inhibition as well as germination of each exposed plant species was calculated for each site sediment. Ostracod exposure tests were conducted as 6 replicates per site sample and 1 control per sample by using reference sediment (consisting of washed marine sediment less than $2 \mathrm{~mm}$ in size) according to the standard operating procedures of the test kit (Ostracodtoxkit F, 2001) and the ISO (2012) method. Ostracod neonates were exposed to test sediments (6 days in darkness at $25^{\circ} \mathrm{C} \pm 2^{\circ} \mathrm{C}$ ). Upon completion of the test period, all surviving ostracods were collected and photographs were taken with a compound microscope (with a built-in digital camera) using a micrometre cover slip as a reference point. Using the UTHSCSA ImageTool (Version 3) software, growth inhibition of surviving ostracods exposed to test sediments was determined in relation to the control exposure. Mortality data were also noted. Data from the two sediment bioassays were analysed using Microsoft Excel.

\section{RESULTS}

\section{Sediment characterisation}

The Wentworth scale classification (Blott and Pye, 2001) for grain size distribution was used to define the sediment from this study. Results from the grain size analysis (Fig. 1) for the upstream site indicated that the sediment mainly consisted of very fine sand (31\%), medium sand (34\%) and coarse sand (29\%). Sediment collected from the ERP largely consisted of medium sand (32\%) and very fine sand (27\%) and to a lesser extent coarse sand (14\%) and mud (15\%). Very fine sand (32\%) and gravel (28\%) were the highest at the downstream site, followed by medium sand (20\%). The TOC was $4 \%$ for the upstream site sediment, $7 \%$ for the ERP site sediment and 3\% for the downstream site sediment.

\section{ICP-OES}

Results from ICP-OES analysis are summarised in Table 1 for elements that were present in all three samples, at or above detection limits.

\begin{tabular}{|c|c|c|c|c|c|}
\hline \multicolumn{6}{|c|}{$\begin{array}{l}\text { TABLE } 1 \\
\text { Total metal concentrations ( } \mathrm{mg} / \mathrm{kg} \text { ) in the collected sediment samples in comparison to the } \\
\text { Canadian Sediment Quality Guideline values }\end{array}$} \\
\hline \multirow{2}{*}{ Element } & \multirow{2}{*}{ Upstream site } & \multirow{2}{*}{ ERP site } & \multirow{2}{*}{ Downstream site } & \multicolumn{2}{|c|}{ CCME, 2001} \\
\hline & & & & ISQG & PEL \\
\hline Al & 7200 & 27600 & 16400 & - & - \\
\hline $\mathrm{Ba}$ & 42 & 92 & 40 & - & - \\
\hline Be & BDL & BDL & BDL & - & - \\
\hline $\mathrm{Ca}$ & BDL & 800 & BDL & - & - \\
\hline $\mathrm{Cr}$ & 296 & 67 & 46 & 37 & 90 \\
\hline $\mathrm{Cu}$ & BDL & 23 & BDL & 36 & 197 \\
\hline $\mathrm{Fe}$ & 12800 & 33600 & 16800 & - & - \\
\hline $\mathrm{K}$ & BDL & 1600 & 680 & - & - \\
\hline $\mathbf{M g}$ & BDL & 800 & 1200 & - & - \\
\hline Mn & 267 & 614 & 133 & - & - \\
\hline $\mathrm{Ni}$ & 16 & 21 & BDL & - & - \\
\hline $\mathbf{P}$ & 13 & 269 & 77 & - & - \\
\hline $\mathbf{P b}$ & BDL & 19 & 10 & 35 & 91.3 \\
\hline $\mathbf{s}$ & 600 & BDL & BDL & - & - \\
\hline Si & 2080 & 2920 & 2040 & - & - \\
\hline Sn & 20 & BDL & 17 & - & - \\
\hline Sr & BDL & 11 & BDL & - & - \\
\hline $\mathrm{Ti}$ & 1296 & 1551 & 2844 & - & - \\
\hline $\mathbf{v}$ & 1013 & 65 & 56 & - & - \\
\hline$Z n$ & 22 & 53 & $\mathrm{BDL}$ & 123 & 315 \\
\hline
\end{tabular}

ISQG: Interim Sediment Quality Guidelines

PEL: Probable Effect Level

BDL: Below the detection level of the ICP-OES. CCME: Canadian Council of Ministers of the Environment

- No guideline values available 
TABLE 2

Results from the Ostracodtoxkit $F$ and Phytotoxkit tests for each sample. Results above the $20 \%$ natural variation indicated in bold (inhibition/mortality and stimulation). US - upstream; ERP - effluent release point; DS - downstream.

\begin{tabular}{|c|c|c|c|c|c|}
\hline \multirow{2}{*}{$\begin{array}{l}\text { Sampling } \\
\text { site }\end{array}$} & \multicolumn{3}{|c|}{ Phytotoxkit test } & \multicolumn{2}{|c|}{ Ostracodtoxkit F test } \\
\hline & L. sativum & S. alba & S. saccharatum & Mortality & Growth inhibition \\
\hline US & $+7 \%$ & $+33 \%$ & $-17 \%$ & $100 \%$ & NA \\
\hline ERP & $-0.4 \%$ & $+13 \%$ & $+5 \%$ & $27 \%$ & $-73 \%$ \\
\hline DS & $-14 \%$ & $-46 \%$ & $-26 \%$ & $30 \%$ & $-76 \%$ \\
\hline
\end{tabular}

+ Result $=$ stimulation

- Result $=$ inhibition

\section{Phytotoxkit and Ostracodtoxkit $\mathrm{F}$ results}

The upstream site sediment exposure indicated $100 \%$ ostracod mortality. Sediment collected from the ERP resulted in $27 \%$ mortality and inhibition of growth in surviving ostracods by $73 \%$. Growth of ostracods exposed to the downstream site sediment was inhibited by $76 \%$, with a $30 \%$ mortality rate.

Phytotoxkit exposure results (Table 2) for the upstream sediment showed growth stimulation for both L. sativum (7\%) and S. alba (33\%) seeds and inhibition (17\%) for S. saccharatum. Exposure results for the ERP sediment indicated that the L. sativum seeds did not show a deviation from the control growth, whilst both S. alba and S. saccharatum seeds were stimulated by $13 \%$ and $5 \%$, respectively. The growth of all three seed species was inhibited with the downstream site sediment. Seeds from $L$. sativum were inhibited by $14 \%$, S. alba by $46 \%$ and S. saccharatum by $26 \%$.

\section{DISCUSSION}

Both grain size and organic content can contribute to the toxicity potential of a sediment sample. Finer sediments have a larger surface area than coarse sediments providing more binding sites for contaminants, whilst organic content has a high affinity to metals (Lin et al., 2003; Simpson et al., 2005). Results from the upstream site indicated that the sediment composition (Fig. 1) was largely composed of very fine to coarse sand $(53 \mu \mathrm{m}-500 \mu \mathrm{m})$ and high TOC according to the USEPA (1991) classification system. ERP sediment grain size distribution ranged between mud and coarse sand $(<53 \mu \mathrm{m}-500 \mu \mathrm{m})$ with a high TOC (USEPA, 1991). The downstream site's sediment was mainly composed of gravel $(4000 \mu \mathrm{m})$ and very fine sand $(53 \mu \mathrm{m})$ with a medium TOC (USEPA, 1991). Al, Ba, Ca, Cu, Fe, $\mathrm{K}, \mathrm{Pb}, \mathrm{Si}, \mathrm{Sr}$ and $\mathrm{Zn}$ levels were higher at the ERP when compared to the upstream and downstream sites, possibly as a result of the higher $<53 \mu \mathrm{m}$ fraction with its increased surface area. Be, $\mathrm{Cr}, \mathrm{S}$, and $\mathrm{V}$ levels decreased from the upstream towards the downstream site, whilst both $\mathrm{Ti}$ and $\mathrm{Mg}$ levels increased from the upstream site towards the downstream site. Cr concentration $(296 \mathrm{mg} / \mathrm{kg})$ at the upstream site was above the Interim Sediment Quality Guidelines (ISQG) (CCME, 2001) value of $37 \mathrm{mg} / \mathrm{kg}$ as well as the Probable Effect Level (PEL) of $90 \mathrm{mg} / \mathrm{kg}$. Cr levels at the ERP $(67 \mathrm{mg} / \mathrm{kg})$ and the downstream site $(46 \mathrm{mg} / \mathrm{kg})$ were above the ISQG and below the PEL. The high S and Cr levels at the upstream site could possibly be from the opencast coal mine and the railway line. A study by Grieve et al. (2001) looked at the metals found in railway tracks and train wheels and how these metals contaminate the environment due to wear-andtear of the wheels and the tracks. They found that the highest $\mathrm{Cr}$ concentration is within a $20 \mathrm{~m}$ distance from the tracks. The agricultural activities (fertilisers) between the river and the opencast coal mine, as well as the opencast mine itself ( $\mathrm{S}$ in coal) could be contributing to the high S levels at the upstream site and could also promote surface water runoff due to the high amounts of water used for the irrigation of crops. Therefore surface runoff and atmospheric deposition could have transported the contaminants to the main river. At all three of the sites the values for Cu were below ISQG values $(36 \mathrm{mg} / \mathrm{kg}$ ) and the PEL $(197 \mathrm{mg} / \mathrm{kg})$. Pb levels at all three sites were also below the ISQG value of $35 \mathrm{mg} / \mathrm{kg}$ and the PEL of $91 \mathrm{mg} / \mathrm{kg}$. Zn levels at all three sites were below the ISQG value of $123 \mathrm{mg} / \mathrm{kg}$ and the PEL of $315 \mathrm{mg} / \mathrm{kg}$. The occurrence of these elements at high levels at all three sites could be due to coal-mining activities in the vicinity of the power station, industrial processes such as steel and iron production as well as fly ash and atmospheric deposition from coal combustion (Tau, 2005; Seshadri et al., 2010; Mahlaba et al., 2011; Ayanda et al., 2012; Ladwani et al., 2012).

Ostracod mortalities at the upstream site (100\%) are possibly due to elevated $\mathrm{Cr}$ and $\mathrm{V}$ concentrations present at this site in comparison to the remaining two sites. Whilst total metal concentrations do not give an indication of metal bioavailability, previous studies conducted have shown a correlation between increased metal concentrations and expressed ostracod mortalities. Additionally, it is acknowledged that whilst a full suite of analysis was not conducted to incorporate other sources of pollution, such as hydrocarbons and pesticides, ostracods have been found to be just as sensitive as or even more sensitive to metal contamination than other freshwater crustaceans (Shuhaimi-Othman et al., 2011). The study by Kudłak et al. (2011) indicated that $H$. incongruence has a high sensitivity to $\mathrm{Cu}$ and $\mathrm{Cr}$. The ERP sediment caused a 73\% growth inhibition in the exposed ostracods and mortalities of $27 \%$, whilst ostracods exposed to the downstream site sediment had a mortality rate of $30 \%$ and growth inhibition of $76 \%$. These results indicated that contamination present in sediments collected in the vicinity of the power station has the potential to result in toxicity in the aquatic environment, especially to more sensitive aquatic species, as indicated by the ostracod exposures.

Phytotoxicity exposures with the Phytotoxkit test kit at the upstream site indicated that seeds from L. sativum and S. alba were stimulated whilst $S$. saccharatum seeds were inhibited. At the ERP L. sativum growth did not differ significantly from the control growth; $S$. alba and $S$. saccharatum were slightly stimulated. At the downstream site all plant seeds exposed were inhibited. The stimulation of L. sativum and S. alba at the upstream site, in comparison to the mortality of the ostracods, could possibly be due to the ability of glutathione (present in the cellular structures of plants) to protect and detoxify the plants of organic chemicals, heavy metals and oxidative stress (Yadav, 2010). The upstream site and the ERP had a higher organic content than the downstream site. This could have contributed to the downstream site indicating a higher toxicity to the plant species. Toxicants bound to 
organics would reduce potential toxicity. Seeds used in the test have enough energy required for germination and growth during test exposure and would not be influenced by a lack of nutrients in test sediment, thus only indicating the toxicity of the sediment itself (Persoone, 2013). The results from a study by Czerniawska-Kusza et al. (2006) showed that growth inhibition and stimulation effects can vary between plant species due to the sediment contaminant composition.

The findings from this study show that the Phytotoxkit and the Ostracodtoxkit $\mathrm{F}$ are sensitive enough to indicate sediment toxicity. Past studies have shown that results from the ostracod test kit are comparable to those from the Hyalella azteca and Chironomus riparius tests when assessing sediment toxicity (Chial and Persoone, 2003).

\section{CONCLUSION}

In this study, the two microbiotests applied proved useful in determining the potential toxicity of contaminated river sediment. Although there is an observed correlation between the mortality results and the metal concentrations, it is acknowledged that other contributing factors (e.g. PCBs and PAHs) were not analysed during this study as they were not identified as primary chemicals of concern. In further studies, sediment physical characteristics as well as potential chemicals of concern should be addressed in order to improve the correlation between observed effects and risk.

\section{ACKNOWLEDGEMENTS}

The authors wish to thank the Water Research Commission (WRC) for the funding they provided for this study.

\section{REFERENCES}

AYANDA OS, FATOKI OS, ADEKOLA FA and XIMBA BJ (2012) Characterization of fly ash generated from Matla Power station in Mpumalanga, South Africa. Electron. J. Chem. 9 (4) 1788-1795. https://doi.org/10.1155/2012/451801

BLAISE C (1991) Microbiotests in aquatic ecotoxicology: characteristics, utility, and prospects. Environ. Toxic. Water 6 145-155. https://doi.org/10.1002/tox.2530060204

BLOTT SJ and PYE K (2001) GRADISTAT: A grain size distribution and statistics package for the analysis of unconsolidated sediments. Earth. Surf. Process. 26 1237-1248. https://doi.org/10.1002/esp.261

CCME (Canadian Council of Ministers of the Environment) (2001) Canadian Sediment Quality Guidelines for the Protection of Aquatic Life: Summary Table. Canadian Council of Ministers of the Environment, Winnipeg. https://doi.org/10.1002/tox.10135

CHIAL B and PERSOONE G (2003) Cyst-based toxicity tests XVapplication of Ostracod solid-phase Microbiotest for toxicity monitoring of contaminated soils. Environ. Toxicol. 18 347-352.

CZERNIAWSKA-KUSZA I and KUSZA K (2011) The potential of the Phytotoxkit microbiotest for hazard Evaluation of sediments in eutrophic freshwater ecosystems. Environ. Monit. Assess. 179 113-121. https://doi.org/10.1007/s10661-010-1722-y

CZERNIAWSKA-KUSZA I, CIESIELCZUK T, KUSZA G and CICHON A (2006) Comparison of the Phytotoxkit microbiotest and chemical variables for toxicity evaluation of sediments. Environ. Toxicol. 21 367-372. https://doi.org/10.1002/tox.20189

DALLAS HF and DAY JA (2004) The effect of water quality variables on aquatic ecosystems: A Review. WRC Report No. TT224/04. Water Research Commission, Pretoria.
GIMÉNEZ MC, BLANES PS, BUCHHAMER EE, OSICKA RM, MORISIO Y and FARÍAS SS (2013) Assessment of heavy metals concentration in arsenic contaminated groundwater of the Chaco Plain, Argentina. ISRN Environ. Chem. 2013 Article ID 930207. http://dx.doi.org/10.1155/2013/930207. https://doi. org/10.1155/2013/930207

GRIEVE DG, DWYER-JOYCE RS and BEYNON JH (2001) Abrasive wear of railway track by solid contaminants. Proc. Inst. Mech. F 215 (Part F) 193-205. https://doi.org/10.1243/0954409011531512

ISO (INTERNATIONAL STANDARDS ORGANISATION) (2012) Water quality - determination of freshwater sediment toxicity to Heterocypris incongruens (Crustacea, Ostracoda). ISO 14371.

JAIN MK, DADHICH LK and KALPANA S (2012) Heavy metals contamination in sediments of the River Parbati, Baran, Rajasthan. J. Chem. Biol. Phys. Sci. 2 (1) 54-60.

KUDŁAK B, WOLSKA L and NAMIESNIK J (2011) Determination of EC50 toxicity data of selected heavy metals toward Heterocypris incongruens and their comparison to "direct-contact" and microbiotests. Environ. Monit. Assess. 174 509-516. https://doi. org/10.1007/s10661-010-1474-8

LADWANI KD, MANIK VS and RAMTEKE DS (2012) Assessment of heavy metal contaminated soil near coal mining area in Gujarat by toxicity characteristics leaching procedure. IJLBPR 1 (4). http://www. ijlbpr.com/currentissue.php.

LATIF M and LICEK E (2004) Toxicity assessment of wastewaters, river waters, and sediments in Austria using cost-effective microbiotests. Environ. Toxicol. 19 (4) 302-309. https://doi.org/10.1002/tox.20027

LIN JG, CHEN SY and SU CR (2003) Assessment of sediment toxicity by metal speciation in different particle-size fractions of river sediment. Water Sci. Technol. 47 (7-8) 233-241.

MAHLABA JS, KEARSLEY EP and KRUGER RA (2011) Physical, chemical and mineralogical characterisation of hydraulically disposed fine coal ash from SASOL Synfuels. Fuel 90 (7) 2491-2500. https://doi.org/10.1016/j.fuel.2011.03.022

OSTRACODTOXKIT F (2001) Chronic "direct contact" toxicity test for freshwater sediments. Standard Operational Procedure. Creasel, Dienze, Belgium. 18 pp.

PERSOONE G (2013) Personal communication, 1 August 2013. Prof. Guido Persoone, Laboratory of Environmental Toxicology and Aquatic Ecology, Ghent University, Ghent, Belgium.

PHYTOTOXKIT (2004) Seed germination and early growth microbiotest with higher plants. Standard Operational Procedures. MicroBioTests Inc., Nazareth, Belgium. 24 pp.

SESHADRI B, BOLAN NS, NAIDU R and BRODIE K (2010) The role of coal combustion products in managing the bioavailability of nutrients and heavy metals in soils. J. Soil Sci. Plant Nutr. 10 (3) 378-398. https://doi.org/10.4067/s0718-95162010000100011

SHUHAIMI-OTHMAN M, YAKUB N, RAMLE N and ABAS A (2011) Toxicity of metals to a freshwater ostracod: Stenocypris major. J. Toxicol. 2011 Article ID 136104. https://doi.org/10.1155/2011/136104

SIMPSON SL, BATLEY GE, CHARITON AA, STAUBER JL, KING CK, CHAPMAN JC, HYNE RV, GALE SA, ROACH AC and MAHER WA (2005) Handbook for Sediment Quality Assessment. Centre for Environmental Contaminants Research, CSIRO Energy Technology, Bangor, New South Wales. $117 \mathrm{pp}$.

TAU P (2005) Occupational hazards of exposure to coal fly ash. MSc dissertation, Tshwane University of Technology, Pretoria, South Africa.

TOROKNE A and TORO K (2010) Evaluation of the toxicity of river and creek sediments in Hungary with two different methods. Environ. Toxicol. https://doi.org/10.1002/tox.20595.

VAN DER VLIET L, VELICOGNA J, PRINCZ J and SCGROGGINST R (2012) Phytotoxkit: A critical look at a rapid assessment tool. Environ. Toxicol. Chem. 31 316-323. https://doi.org/10.1002/etc.743

USEPA (United States Environmental Protection Agency) (1991) Description and sampling of contaminated soil: A field pocket guide. Report EPA/625/12-91/002. USEPA, Ohio.

YADAV SK (2010) Heavy metals toxicity in plants: An overview on the role of glutathione and phytochelatins in heavy metal stress tolerance of plants. S. Afr. J. Bot. 76 167-179. 